http://jmscr.igmpublication.org/home/ ISSN (e)-2347-176x ISSN (p) 2455-0450

crossref DOI: https://dx.doi.org/10.18535/jmscr/v8i2.113

\title{
Prevalence of Musculoskeletal Disorders among Dentists in Ernakulam District-A Cross-Sectional Study
}

Authors

\author{
Kajel Anna Mani ${ }^{1}$, Dr Sarasa.T.P. ${ }^{2}$, Dr Nafeesath Beevi ${ }^{3}$ \\ ${ }^{1}$ PG Scholar, Department of Swasthavritta, Govt. Ayurveda College, Tripunithura \\ ${ }^{2}$ Former Professor \& HOD. Department of Swasthavritta, Govt. Ayurveda College, Tripunithura \\ ${ }^{3}$ Associate Professor, Department of Swasthavritta, Govt. Ayurveda College, Tripunithura
}

\begin{abstract}
Background and Objectives: Occupational health problems are increasingly common worldwide during the past decades. National and state government have recognised the need to protect the occupational health of the people since the development of nation depends upon its manpower. Practising dentistry is not an easy task because it involves repetitive, awkward and stressful movements of hands and wrists and have to contort their body while using variety of hand tools to perform work in the oral cavity. So musculoskeletal disorders are very common among the dentists. This study was to find out the prevalence of musculoskeletal disorders among the dentists in Ernakulam district.
\end{abstract}

\section{Methods}

Design: Cross-sectional study.

A modified semi-structured questionnaire based on Nordiac questionnaire was distributed to 238 dentists selected by cluster random sampling, working in various dental clinics and dental colleges of Ernakulam district and data related to musculoskeletal disorders and lifestyle of the dentists were collected.

Results and Discussion: By analysing the data, an overall prevalence of musculoskeletal disorders among dentists in Ernakulam district was 78.6\%. Continuous work load, prolonged static and awkward postures are considered to be the main causative factor for musculoskeletal disorders. So application of proper ergonomics, postural corrections and implementation of Ayurvedic diet and regimens and Yoga practice can help the dentists to overcome the musculoskeletal disorders which occurred as a result of their profession.

Conclusion: The prevalence of musculoskeletal disorders among dentists in Ernakulam district is very high. The most affected joint in dentists is Neck.58.4\% of dentists complained of problem in neck region. Next most affected joints were Low-back and Upper back. From this survey among the dental specialities,

Orthodontists, Endodontists Prosthodontists, paediatric dentists and dental surgeons are at higher risk of MSD.

Keywords: Musculoskeletal disorders, Dentists, Survey.

\section{Introduction}

Musculoskeletal disorders have become major health problem in various field of jobs including teachers, IT professionals and also the doctors, especially the dentists. Practising dentistry cannot be considered as an easy task since it involves repetitive, awkward and stressful movements of hands and wrists. Dentists have to contort their 
body while using a variety of elaborate hand tools in order to perform work in the oral cavity. They are required to maintain these positions for prolonged periods of time. This creates a problem of having static contractions and subsequently developing muscle ischemia, which cause myofacial trigger points, which can result in pain, restriction of movement and muscular atrophy. This can result in discomfort pain and illness that can result in disruption or impairment in dental practice. Due to the unbalanced and prolonged postures dentists would have overstrain at tendons and joints which may result in chronic inflammation and weakness.

\section{Methodology}

$\begin{array}{lll}\text { 1.Study Design } & : & \begin{array}{l}\text { Cross-sectional study } \\ \text { Dental colleges and }\end{array} \\ \text { 2.Study Setting } & : & \text { Dental clinics in }\end{array}$

$\begin{array}{lll}\text { 3.Study Population } & : & \text { Practising dentists } \\ \text { 4.Study Period } & : & 18 \text { months. }\end{array}$

\section{Inclusion Criteria}

1) Working dentists of age group 28-45yrs.

2) At least $2 y r s$ of working experience

\section{Exclusion Criteria}

1) Dentists having Rheumatoid arthritis, Tuberculosis, Malignancy.

2) Dentists having other chronic systemic illness.

3) Dentists of age below 28 and above 45

\section{Sample Size -238}

\section{Sampling Technique}

Cluster random sampling.

\section{Data Collection}

The data collected through direct interview schedule using a combined and modified version of semi structured questionnaire.

\section{Study Tool}

Data collected with the help of a combined and modified version of Semi structured Nordiac questionnaire. $^{1}$

\section{Procedure}

Descriptive studies are concerned with observing the distribution of disease or health related characteristics in human population and identifying the characteristics with which the disease in question seems to be associated. Crosssectional studies are based on a single examination of a cross-section of population at one point in time. It is also known as Prevalence study. $^{2}$

Questionnaire survey was decided to be adopted in this case as it is more feasible for obtaining the data, and it's analysis within a short period of time. A modified version of Nordic questionnaire including questions on lifestyle assessment was prepared.

The modified questionnaire was distributed to various private dental clinics in following places.

1) Tripunithura

2) Aluva

3) Angamaly

4) Kothamangalam

5) Muvattupuzha

6) Perumbavoor

7) Piravam

8) Koothattukulam

The questionnaire was distributed in following dental college.

1) Annoor Dental College. Muvattupuzha.

2) Mar Baselious Dental College. Kothamangalam

3) Mar Ignatious Dental College. Kothamangalam.

From these dental units 238 dentists were selected meeting the inclusion criteria. The data was collected through direct interview schedule using modified version of Nordic questionnaire. Individual consent was obtained and they were assured about the confidentiality of any kind of data obtained through survey and their duty time was not interrupted for data collection.

The data obtained was compiled, coded and tabulated. The data is statistically analysed for any significance and conclusions are made 


\section{JMSCR Vol||08||Issue||02||Page 656-660||February}

Observations, Analysis \& Interpretation

Distribution According To Specialisation

\begin{tabular}{|l|c|c|}
\hline & Frequency & Percentage \\
\hline BDS only & 98 & $41.1 \%$ \\
\hline Pediatric & 26 & $18.60 \%$ \\
\hline Orthodontics & 25 & $17.80 \%$ \\
\hline Endodontics & 19 & $13.60 \%$ \\
\hline Prosthodontics & 28 & $10.70 \%$ \\
\hline Periodontics & 15 & $20 \%$ \\
\hline Surgeon & 12 & $8.60 \%$ \\
\hline Others & 15 & $10.70 \%$ \\
\hline Total & 238 & $100 \%$ \\
\hline
\end{tabular}

Distribution according to Working Hours per Day

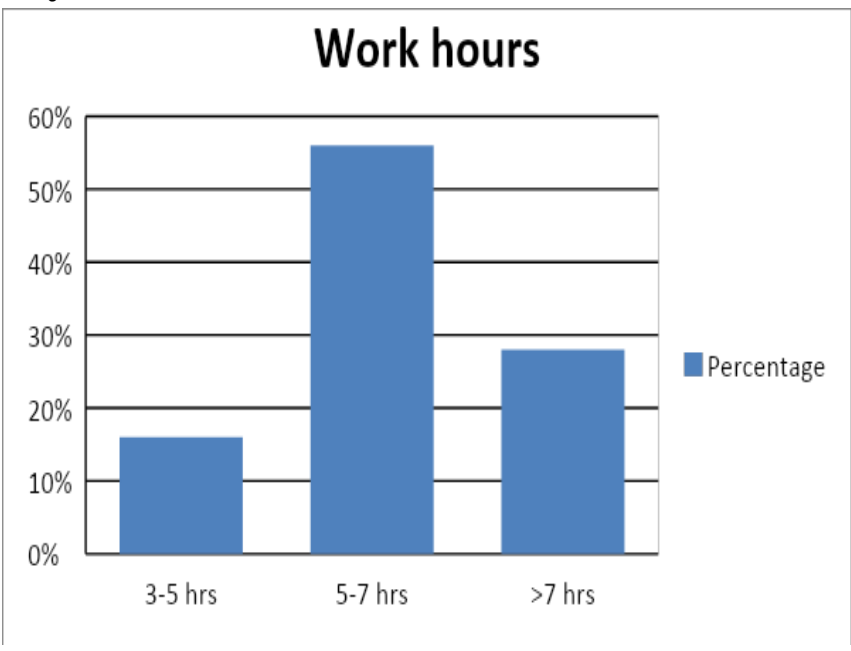

Distribution according to time of Continuous Work

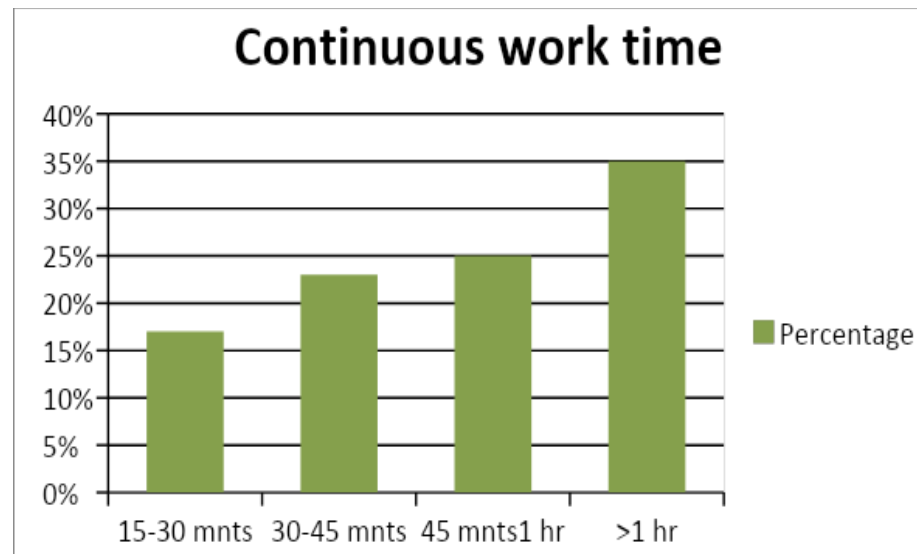

Distribution according to Working Posture

\section{Working Posture}

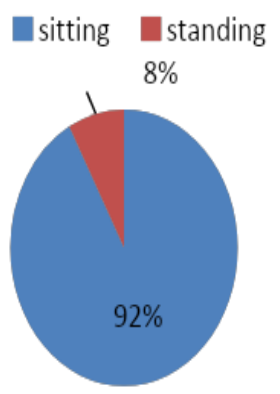

Distribution according to data related to Morbidity

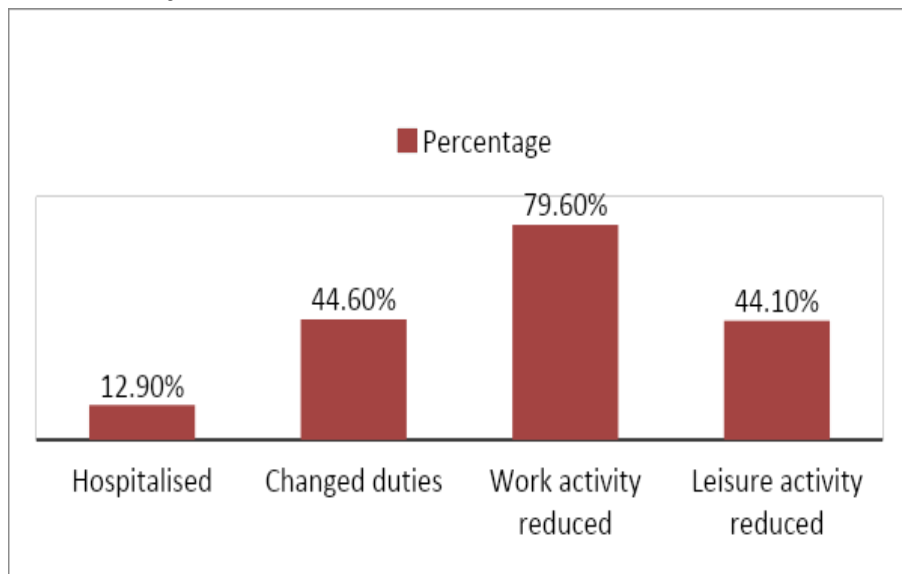

Observations on Musculo-Skeletal Complaints Distribution according to Trouble (Pain, Ache, Discomfort) During Last 12 Months

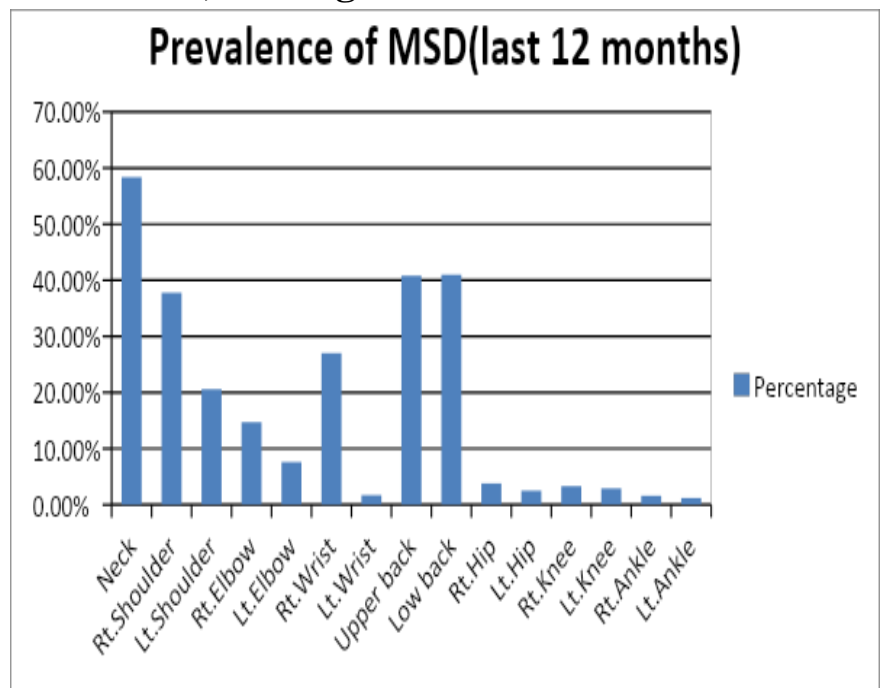


Distribution according to Trouble (Pain/Ache/ Discomfort) During Last 12 Months That Prevented Normal Work

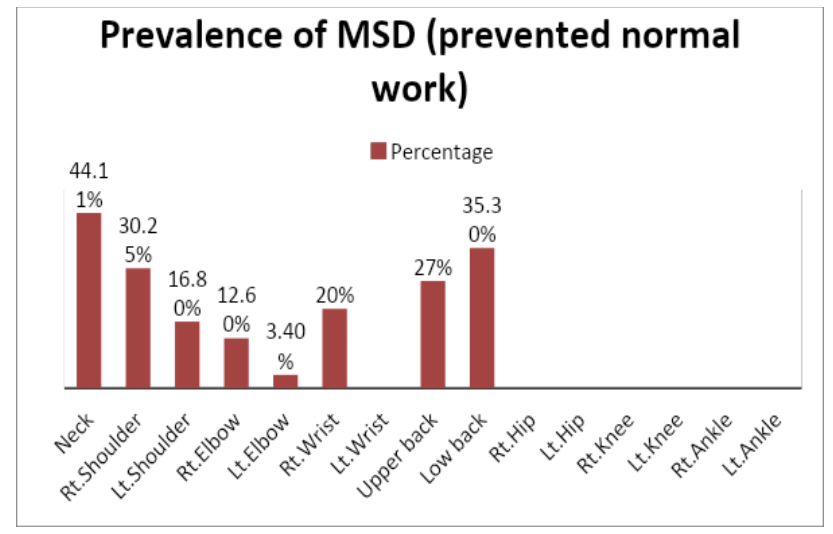

Distribution according to Trouble (Pain, Ache, Discomfort) during the last Seven Days.

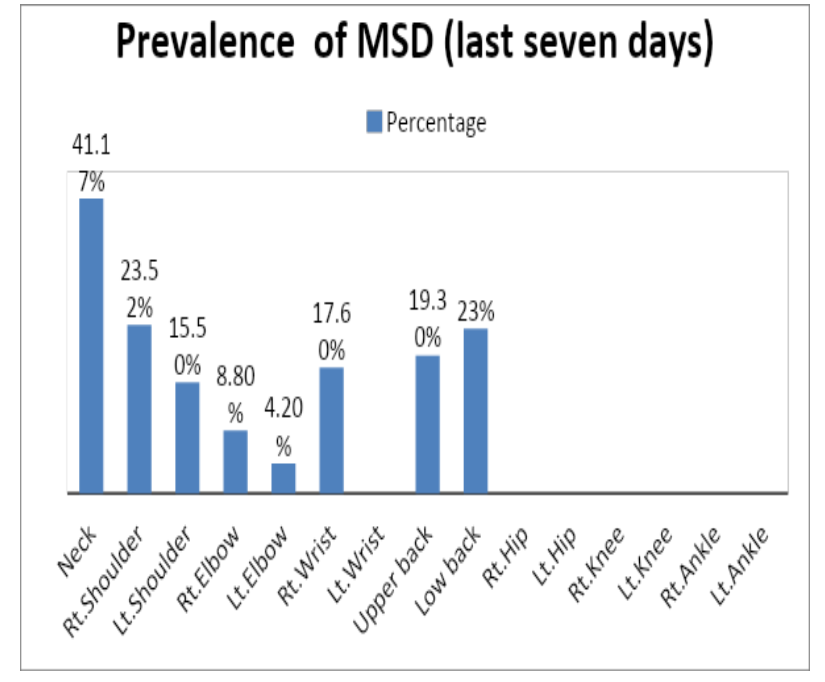

Over All Prevalence of MSD among Dentists (Last 12 months period)

\section{Over all Prevalence of MSD}

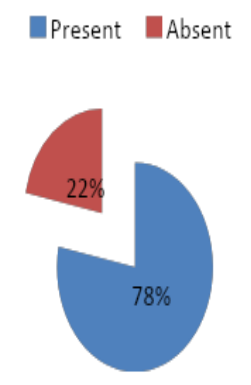

\section{Discussion}

Healthy practitioners are particularly important for a successful dental practice and well- being of the patient. Evidence shows that unique working conditions in dentistry can significantly affect the health of dentists. Dentists such as other health- care providers have occupation- related health problems mainly including neck and low back pain, allergies to latex, injuries from needles, and sharp instruments ${ }^{3}$

In the present study, the analysis was done for the observations obtained from the modified Nordiac musculoskeletal questionnaire to find out the data related to the prevalence of musculoskeletal disorders among the subjects. The observations were obtained from the questionnaire for the musculoskeletal pain for various sites namely neck, shoulders, upper back, lower back, elbows, wrist, hip, knees and ankle.

An overall prevalence of $78 \%$ was reported. This prevalence rate was almost near to prevalence rate of MSD among dentists in Australia and Israel. ${ }^{4}$ Also from this data we can see that the most affected joint in dentists is Neck.58.4\% of dentists complained of problem in neck region In dentists the prolonged flexion, extension, lateral bending and twisting of the neck induce muscle fatigue, and may lead to chronic muscle injuries and degenerative changes of the cervical spine. Postures where the neck is bent forward for prolonged periods of time-several hours-are common in dentists. Repetitive movements performed by the hands increase the demands on stabilization of the neck and shoulder region, and thereby increase the risk of neck complaints. ${ }^{5}$

The next most affected regions are low back (41\%) and upper back (40.8\%). Prolonged static flexed spine posture of dentists induces high pressure on discs. This "creep" results from the continuing deformation of the disc structures and also from fluid loss. This can finally lead to degenerative changes. Also fatigue due to sustained or repetitive movements or sudden overexertion of muscles or ligaments can cause low-back pain. ${ }^{6}$

The next affected joint was right shoulder. $96 \%$ of dentists was right handed. That may be the reason for more prevalence of MSD in right shoulder $(37.8 \%)$ than the left shoulder (20.58\%). 
Compared to other joints the flexibility of glenohumeral joint is greater but its stability is less. The ligaments are weak and the strength is mainly due to rotator cuff muscles. When the arm is raised and bent either away from or towards the body (abduction or flexion), a lever is created in which the distance from the centre of gravity increases, and hence the twisting force, and the loading torque, on the glenohumeral joint increases. The rate, at which the torque increases, however, is not simply directly proportional to the angle at which the arm is bent, because the mathematical function which describes the biomechanical forces is not linear but is rather a sine function of the abduction angle. The torque will decrease only by about $10 \%$ if the flexion or abduction angle is decreased from 90 to 60 degrees. So while practising various procedures in dentistry, the arm is in abducted posture for prolonged period without proper support. So the torque will be very high and it leads to muscle fatigue and pain. ${ }^{7}$

When we observe joints in lower limbs the prevalence of MSD is very low compared to upper region. While considering an occupational problem it is very important to assess how much the problem affects their normal work. Among the dentists it is the neck, low back and shoulder are the main site of msd that prevented doing normal work. Also we can notice that even though there was slight msd in lower limbs, no dentists complained of it affecting their normal work. Since the msd of upper trunk is interfering in normal work of dentists, it will certainly affect the efficiency of dental practice.

\section{Conclusion}

There is high prevalence of $78.6 \%$ of musculo-skeletal disorders among dentists in Ernakulam district.

Among the dental specialities, Orthodontists, Endodontists, Prosthodontists, paediatric dentists and dental surgeons are at higher risk of MSD.
The most affected joint in dentists is Neck.58.4\% is the prevalence rate of neck disorders in dentists.

There is high prevalence of MSD in Low back, Upper back and Shoulder region.

\section{References}

1. Kuorinka, Jonsson, B. Kilbom Standardised Nordic Questionnaires for the Analysis of Musculoskeletal Symptoms Applied Ergonomics Vol 18 No 3 (1987)pp.233-237

2. K. Park Park's Textbook of Preventive and social medicine Bhanot Publications; 23rdedition 2015 chap. 2 page 14

3. Vinay Kumar Bhardwaj, Rajeshwar Prasad Luthra, Deepak Sharma, Anil Chug, Manish Sahore, Aditya Sharma Self- reported occupational health problems among dentists in Himachal Pradesh, India: A descriptive survey International Journal of Health \& Allied Sciences Vol. 2 Issue 2 Apr-Jun 2013 Available at $\mathrm{m}$ http://www.ijhas.in (accessed on $1 / 1 / 2019$ )

4. PA Leggat DR Smith Musculoskeletal disorders self-reported by dentists in Queensland, Australia. Australian Dental Journal 2006;51:(4):324-327 Available at www.ncbi.nlm.nih.gov/m/pubmed/17256307 (accessed on 3/1/2019

5. World health organisation. Health topics, Occupational health [Online]: http://www.who.int/topics/occupational_healt h/en/ [Accessed on 15/01/18].

6. World health organisation. Health topics , Occupational health [Online]: http://www.who.int/topics/occupational_healt h/en/ [Accessed on 15/01/18].

7. PA Leggat DR Smith Musculoskeletal disorders self-reported by dentists in Queensland, Australia. Australian Dental Journal 2006;51:(4):324-327 Available at www.ncbi.nlm.nih.gov/m/pubmed/17256307 (accessed on 3/1/2019. 